\title{
Oceanic Effect on Precipitation Development in the Maritime Continent during Anomalously-Wet Dry Seasons in Java
}

\author{
Erma Yulihastin, Muhammad F P, Suaydhi and Iis Sofiati \\ Center of Atmospheric Research and Technology, National Research and Innovation Agency, Bandung, West Java, \\ 40173, Indonesia
}

Received: 2021-03-02 Accepted: 2021-09-20

\section{Keywords:}

Anomalously-wet dry season; Maritime Continent;

Precipitation;

ENSO;

IOD

Correspondent email: erma.yulihastin@brin.go.id

\begin{abstract}
Anomalous rainfall during the dry season over the tropical region is determined by sea surface temperature (SST) anomalies driven by remote forcing. Anomalous precipitation during the dry season in Java (the so-called "anomalously-wet dry season") has increased the number of hydrometeorological disasters, with notable events occurring in 2010, 2013, and 2016. Here we analyze anomalously-wet dry seasons in Java from 2000 to 2019 using variables such as precipitation, wind, temperature, outgoing longwave radiation, and SST obtained from the Tropical Rainfall Measuring Mission and ERA5 European Centre for Medium-Range Weather Forecasts (ECMWF) reanalysis. This study focuses on anomalously-wet dry seasons in Java during the absence periods of negative phase for the El Niño Southern Oscillation (ENSO) and/or Indian Ocean Dipole (IOD) by identification the main caused. The results show that the contribution of local seas is more significant (37\%) in developing anomalously-wet dry seasons than La Niña (33\%), the IOD and La Niña combined (17\%), and the IOD alone (13\%). Local Indonesian seas play a significant role in causing extreme precipitation and spread over the Maritime Continent. We also find that SSTs in the southern Java Sea are sensitive to a negative IOD, but not to La Niña.
\end{abstract}

O2021 by the authors. Licensee Indonesian Journal of Geography, Indonesia.

This article is an open access article distributed under the terms and conditions of the Creative Common

Attribution(CC BY NC) licensehttps://creativecommons.org/licenses/by-nc/4.0/.

\section{Introduction}

Due to the arrangement of ocean and land, the complex topographic distribution, and having the longest coastline in the world, the Maritime Continent (MC) experiences highly concentrated precipitation (Qian, 2008; Ogino et al., 2016; Yamanaka, 2016; Yamanaka et al., 2018). The MC also affects global climate through multiscale interactions on diurnal to interannual timescales (Yamanaka et al., 2018). These multiscale interactions are the result of ocean-atmosphere interactions that occur on subdaily timescales and influence seasonal variations (Li et al., 2020). The warming (cooling) of the sea surface temperature (SST) in the South Indian Ocean is associated with increased (decreased) precipitation over West Sumatra and West Java during the South Asian monsoon (McBridge et al., 2003; Hamada et al., 2012; AsSyakur et al., 2014; Li et al., 2020). Lestari et al. (2019) and Kurniadi et al. (2021) also noted that both the Indian Ocean Dipole (IOD) and El Niño Southern Oscillation (ENSO) are important in the development of extreme rainfall over Indonesia, particularly over West Java. The oceanatmosphere interactions in this region are manifested by a northerly flow that crosses the equator and cools the SST in the South China Sea (Yulihastin et al., 2020).

Studies of ocean-atmosphere interactions in the MC can help improve regional climate models (Thompson et al., 2018; Li et al., 2020). Several ocean-atmosphere interaction studies explored the remote effects of the Pacific and Indian oceans on precipitation over the MC (Ham et al., 2017), as they have been found to influence the seasonal variability over the region (Hamada et al., 2012; As-Syakur et al., 2014; $\mathrm{Xu}$ et al., 2019). A study on the local seas by Aldrian and Susanto (2003) highlighted the role of SST warming in the Moluccas Sea and its interaction with the Indonesian Throughflow, which influences the formation of precipitation in the Moluccas. In addition, Hendon (2003) reported that local SSTs have a strong in-phase correlation with the IndoPacific SST during the dry season as a response to ENSO events. They also showed that an anomalously-wet dry season over Indonesia can occur independently of ENSO. However, the contribution of local seas in influencing the anomalouslywet dry season over southern Indonesia has not yet been explored. Anomalously-wet dry seasons often cause extreme precipitation and flooding in Java; for example, the large floods that occurred due to heavy and persistent precipitation during the dry seasons of 2010, 2013, and 2016 (Suprapto, 2017).

It has been reported that the anomalously-wet dry season over Java appears to be related to the high SST variability during the May-to-September (MJJAS) monsoon period in the southern Java Sea (Qu et al. 1994). Warm SSTs play a role in controlling the humidity and in triggering convective activity during the dry season. The current study aims to advance our understanding of ocean-atmosphere interactions, specifically by assessing the contribution of the 
southern Java Sea in weakening the Australian monsoon and controlling seasonal anomalies in Java.

We investigate anomalously-wet dry seasons in Java and the main causes thereof, considering both remote and local forcing. We consider the influence of the negative phases of ENSO (i.e., La Niña) and the IOD, which represent the remote forcing. We analyze various oceanic and atmospheric parameters that show the regional characteristics of the MC in the four categories of anomalously-wet dry seasons that occur in Java (see Section 2); i.e., a negative IOD and a La Niña event (IO-La), a negative IOD and no La Niña event (IO-nLa), a neutral IOD and a La Niña event (nIO-La), and a neutral IOD and no La Niña event (nIO-nLa). These regional characteristics are needed to determine the role of local seas in the MC in generating anomalously-wet dry seasons.

\section{Methods}

In this study, we define an anomalously-wet dry season as one where the precipitation exceeds $50 \mathrm{~mm}$ in any 10-day period during MJJAS. We used data during May-September (MJJAS) from 2000 to 2019 to capture seasonal precipitation signals over the MC. This period was chosen because hydrometeorological disasters have occurred frequently in this period over the last decade (Suprapto, 2017). We consider the 10-day mean precipitation over Java Island from April to October and define the onset of the dry season as three consecutive 10-day periods of $<50 \mathrm{~mm}$ precipitation (Satyawardhana et al., 2018).

To study the impact of local forcing on the development of anomalously-wet dry seasons, we composite monthly mean data from May to September during neutral years in which there were no IOD or ENSO events. The absence of a negative phase of the IOD and ENSO means the data are free from remote forcing and allow us to investigate the local forcing signal. In this study, the IOD and ENSO indices are obtained from the monthly index data of the National Oceanic and Atmospheric Administration (NOAA) and we use the three-month running average, given that IOD (Saji and Yamagata, 2003) and ENSO (Trenberth, 2007) last for at least three consecutive months.

We use daily precipitation data from the 3B42 dataset of the Tropical Rainfall Measuring Mission (TRMM) satellite with a spatial resolution of $0.25^{\circ}$ (Huffman et al., 2007; Huffman et al., 2012), which has been calibrated by the TRMM Combined Instrument and TRMM Microwave Imager precipitation products (Harris et al., 2007; Liu et al., 2008; Yong et al., 2015). Monthly wind, surface temperature, outgoing longwave radiation (OLR), and daily SST data were obtained from the ERA5 reanalysis data of the European Center for Medium-Range Weather Forecasts (ECMWF) with a spatial resolution of $0.25^{\circ}$ (Hersbach et al., 2017).

Furtherly, the cross-correlation provides quantitative support for the discussion regarding the cross-correlation between rainfall and the indices for the IOD, La Niña, and Australian winter monsoon. The cross-correlation was determined using the following equation:

$$
r_{x y}=\frac{\sum_{i=1}^{n}\left(x_{i}-\bar{x}\right)\left(y_{i}-\bar{y}\right)}{\sqrt{\sum_{i=1}^{n}\left(x_{i}-\bar{x}\right)^{2}} \sqrt{\sum_{i=1}^{n}\left(y_{i}-\bar{y}\right)^{2}}}
$$

where $\mathrm{n}$ is sample size; $\mathrm{x}_{\mathrm{i}}, \mathrm{y}_{\mathrm{i}}$ are the individual sample points indexed with $i$; and $x, y$, are precipitation and the indices of ENSO, IOD, AUSMI, respectively.

Climatological, composite, and anomalous values of atmospheric and oceanic parameters over the MC (Figure 1) are calculated as follows. (1) Climatological conditions are calculated using the equation $X(t)=\frac{\sum_{i=1}^{n} \bar{X}_{i}}{n}$, where $\bar{X}_{i}$ is the monthly mean of a particular parameter (e.g., surface temperature, SST, wind, moisture transport, OLR, precipitation) in the $i$-th year and $n$ is the number of years. The dry season climatology is calculated in MJJAS from 2000 to 2019. (2) Composite calculations are performed based on four situations: a negative phase of the IOD and a La Niña event (IO-La), a negative phase of the IOD and no La Niña event (IO-nLa), a neutral IOD and a La Niña event (nIO-La), and a neutral IOD and no La Niña event (nIO-nLa) (Table 1). (3) Anomaly values of the surface temperature, SST, OLR, precipitation, and moisture transport are calculated as the difference between the composite value and the climatological value. Moisture transport from remote regions is key to the initiation and maintenance of heat driving the monsoon (Fasullo and Webster, 2003). Moisture transport can be obtained from the vertical integral of the water vapor flux as follows:

$Q=\frac{1}{g} \int_{p t}^{p s} q V d p$

, where $Q$ is the water vapor transport $\left(\mathrm{kg} \mathrm{m}^{-1}\right.$ $\left.\mathrm{s}^{-1}\right), g$ is the gravitational acceleration of the Earth $\left(\mathrm{m} \mathrm{s}^{-2}\right), q$ is the specific humidity $\left(\mathrm{g} \mathrm{kg}^{-1}\right), V$ is the zonal-meridional wind vector, $d p$ is the change in pressure $(\mathrm{hPa}), p s$ is the surface pressure $(1000 \mathrm{hPa})$, and pt is the pressure at $850 \mathrm{hPa}$.

\section{Results and Discussion \\ Dry Season Variability in Java}

Precipitation over Java shows an annual oscillation pattern with a maximum during November-to-March (Aldrian and Susanto, 2004). During the dry season, monthly mean precipitation is $<150 \mathrm{~mm}$ (Figure 1). However, precipitation variability on interseasonal and interannual time scales can produce positive monthly precipitation anomalies during the dry season, as was the case in 2000, 2001, 2007, 2010, 2013, and 2016. These are referred to hereinafter as anomalously-wet dry seasons. Variations in monthly mean precipitation can be seen in the 10-day precipitation time series shown in Figure 2. The onset of the dry season is defined as when the precipitation is $<50 \mathrm{~mm}$ which is consistently followed by the next two of 10-days (Satyawardhana et al., 2018).

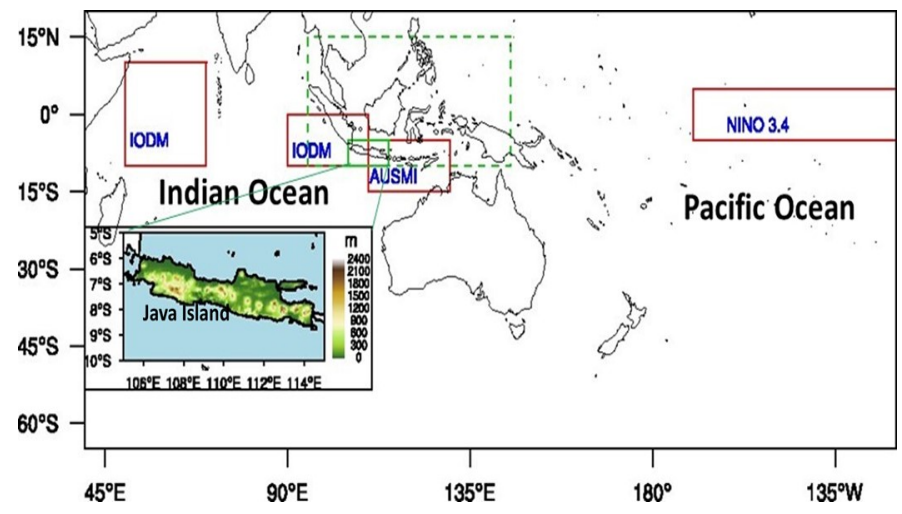

Figure 1. Java Island. The solid green rectangle shows the area-averaged precipitation used for further analysis in Figure 2, with a land mask for restricted data along the coastline. The dashed green rectangle shows the MC $\left(5^{\circ} \mathrm{S}-15^{\circ} \mathrm{N}, 95^{\circ} \mathrm{E}-105^{\circ} \mathrm{E}\right)$ used for the spatial analysis in Figures 5-12. Solid red rectangles represent the areas used to calculate the Indian Ocean Dipole Mode (IODM), the Australian Summer Monsoon Index (AUSMI), and the Niño 3.4 index for Figures 2 and 3. 

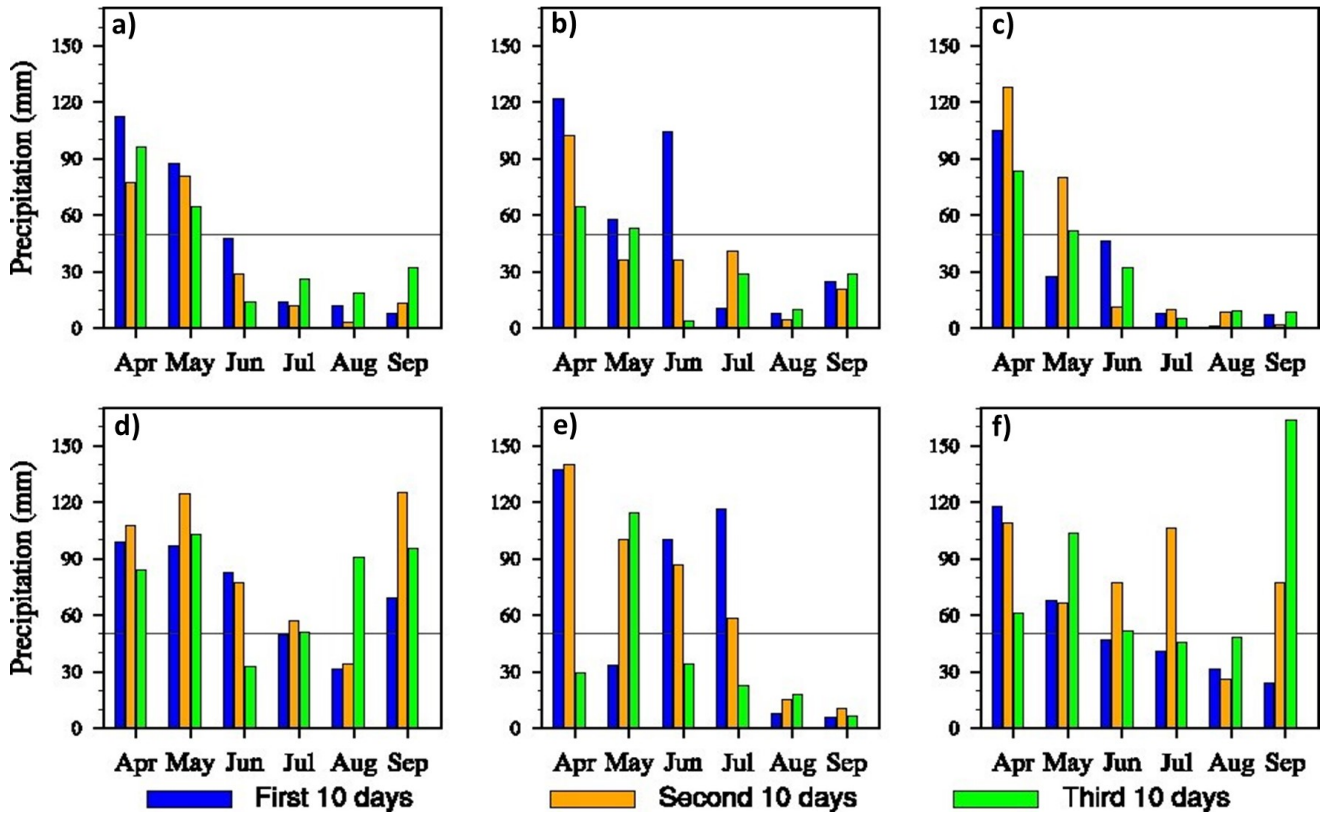

Figure 2. Time series of the 10-day precipitation from April to September for a) 2000, b) 2001 , c) 2007 , d) 2010 , e) 2013 , and f) 2016 . The horizontal grey line represents the threshold value $(50 \mathrm{~mm})$ used to determine the onset of the dry season.

The dry season in Java is strongly influenced by the Australian winter monsoon, as represented by the Australian monsoon index (AUSMI; Kajikawa et al., 2009; Chen and Wang, 2017; Lisonbee et al., 2019). However, in this study, anomalously-wet dry seasons in Java were not found to be consistently influenced by the weakening of the Australian monsoon, except in the monsoon onset periods (May and September), as shown by the cross-correlation analysis in Table 1.

Table 1. Cross-correlation between precipitation over Java Island and the AUSMI, IOD index, and Niño 3.4 index.

\begin{tabular}{cccc}
\hline $\begin{array}{c}\text { Monthly } \\
\text { Precipitation }\end{array}$ & AUSMI & IOD & $\begin{array}{c}\text { ENSO } \\
\text { (Niño3.4) }\end{array}$ \\
\hline May & 0.6078 & -0.6154 & 0.3546 \\
June & 0.0545 & -0.6668 & 0.0126 \\
July & -0.4982 & -0.6409 & -0.2891 \\
August & 0.3544 & -0.5654 & -0.7720 \\
September & 0.5961 & -0.8370 & -0.5372 \\
\hline
\end{tabular}

We conducted a monthly time series analysis of the AUSMI during the anomalously-wet dry seasons in 2000, 2001, 2007, 2010, 2013, and 2016. Figure 3 shows that variations in the AUSMI are not always consistent with variations in the 10-day precipitation (Figure 2). We note that the monsoon is not the only factor determining the seasonal variation of precipitation. Therefore, we also performed a time series analysis to identify interannual oscillations of precipitation caused by ENSO and the IOD (Figure 3).

A cross-correlation analysis was also performed to test the sensitivity of precipitation during anomalously-wet dry seasons in Java to ENSO, AUSMI, and the IOD (Table 1). It appears that the IOD strongly corresponds to anomalous precipitation from May to September, whereas ENSO is only related to anomalous precipitation during the active period of the Australian monsoon (August-September). On the other hand, the AUSMI affected to anomalous precipitation only during the dry season peak of July (Table 1). This result is consistent with previous studies, showing a relatively strong correlation (0.57) between anomalous precipitation over western Java and a negative IOD (Hatmaja et al., 2019).

For case nIO-La during May-September 2000, we find that both ENSO and the IOD had a greater effect on precipitation variability than the Australian winter monsoon, which is consistent with previous studies (Lestari et al., 2019). In this case, the weakening of the La Niña index from May to August was also accompanied by reduced precipitation.
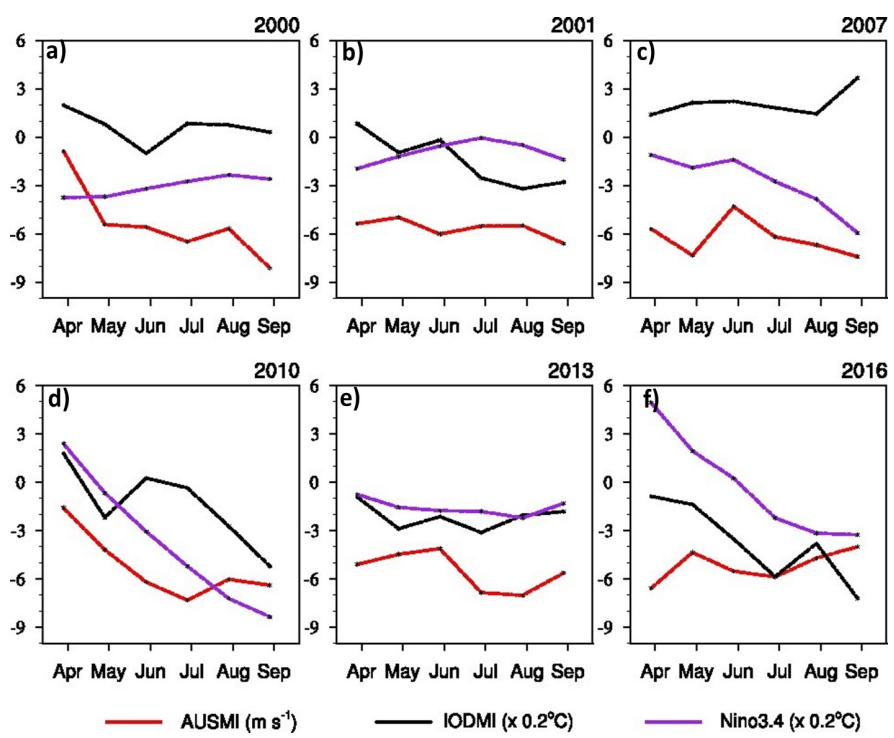

Figure 3. Monthly mean values of the AUSMI (red line), Indian Ocean dipole mode index (ODMI) (black line), and Nino 3.4 index (purple line) during anomalously-wet dry seasons for a) 2000; b) 2001; c) 2007; d) 2010; e) 2013; f) 2016 
Conversely, the strengthening of the AUSMI in September was followed by increased precipitation (Figure 3a). However, in July-September 2007, the strengthening of the AUSMI played a more significant role in reducing precipitation than La Niña (Figure 3c). In June-July 2010, low precipitation (Figure 2d) also corresponded to a strengthening of the AUSMI rather than La Niña (Figure 3d).

On the other hand, during MJJAS the peak precipitation in May and June 2001 in the IO-nLa case (Figure 2b) is not associated with AUSMI variations: decreases in precipitation occurred in August, even when the AUSMI did not vary. Changes in the strength of the negative IOD (Figure 3b) did not appear to influence the precipitation amount in JulySeptember 2001 (Figure 2b). A strengthening negative IOD index did, however, correlate with increased precipitation during June-July 2016 (Figure 3f). This is in agreement with previous work demonstrating that a negative IOD plays a key role in increasing rainfall over western Java Island during the dry season (Hatmaja et al., 2019).

In the IO-La case (August-September 2010), the strengthening La Niña and negative IOD (Figure 3d) appear to be associated with increased precipitation (Figure $2 \mathrm{~d}$ ) and seem to play a more critical role than the AUSMI (Figure 3d). In August-September 2016, a negative IOD, following the weakening of the AUSMI (Figure 3f), resulted in increased precipitation (Figure 2f). Hence, from the crosscorrelation analysis in Table 2 we found that the ENSO tend to independent from IOD but influenced by AUSMI only during the peak of dry season of July. Conversely, the IOD was strong influenced by the ENSO during May-to-July and has a relationship with AUSMI in May, August, and September (Table 3).For the nIO-nLa case, the increase in precipitation from

May to June 2001 (Figure 2b) does not appear to be associated with the AUSMI (Figure 3b). In contrast to May 2007, the maximum precipitation that occurred in June 2007 was associated with a significantly weakened AUSMI (Figure $2 \mathrm{c}$ and 2e). The maximum precipitation in May-July 2013 (Figure 2e) does not seem to be related to the variations in the AUSMI from July to September 2013 (Figure 3e). In this case of nIO-nLa, AUSMI has relationship with ENSO (July) and IOD (May, August, September), respectively (Table 4).

Ocean-Atmosphere Anomalies during Anomalously-Wet Dry Seasons

It should be noted that Figures 2 and 3 do not always indicate a consistent influence of remote forcing on anomalous precipitation over Java during the dry season. Thus, we need to further investigate the characteristics of anomalously-wet dry seasons in the MC caused by La Niña and a negative IOD. The results are shown in Table 5 and

Table 2. Cross-correlation between ENSO (Niño 3.4 index) and the Australian winter monsoon and IOD indices.

\begin{tabular}{crr}
\hline ENSO (Niño3.4) & AUSMI & \multicolumn{1}{l}{ IOD } \\
\hline May & 0,4626 & $-0,4542$ \\
June & 0,1039 & $-0,3538$ \\
July & 0,8114 & $-0,3993$ \\
August & 0,1267 & $-0,0152$ \\
September & 0,1406 & 0,0165 \\
\hline
\end{tabular}

Table 3. Cross-correlation between the IOD index and the AUSMI and ENSO (Niño 3.4 index).

\begin{tabular}{crr}
\hline IOD & AUSMI & \multicolumn{1}{c}{$\begin{array}{c}\text { ENSO } \\
\text { (Niño3.4) }\end{array}$} \\
\hline May & -0.91281 & $-0,45423$ \\
June & 0.07850 & $-0,35382$ \\
July & -0.33168 & $-0,39927$ \\
August & -0.50101 & $-0,01522$ \\
September & -0.78283 & 0,01652 \\
\hline
\end{tabular}

Table 4. Cross-correlation between the AUSMI and ENSO (Niño 3.4 index) and IOD index.

\begin{tabular}{ccc}
\hline AUSMI & $\begin{array}{c}\text { ENSO } \\
(\text { Niño3.4 })\end{array}$ & \multicolumn{1}{l}{ IOD } \\
\hline May & 0,4626 & $-0,9128$ \\
June & 0,1039 & 0,0785 \\
July & 0,8114 & $-0,3317$ \\
August & 0,1267 & $-0,5010$ \\
September & 0,1406 & $-0,7828$ \\
\hline
\end{tabular}

indicate that $63 \%$ of anomalously-wet dry seasons are affected by either ENSO or the IOD (13\% for the IOD-La case, $33 \%$ for the nIO-La case, and $17 \%$ for the IO-nLa case), while $37 \%$ of anomalously-wet dry seasons are not related to either ENSO or the IOD.

Following the classification of anomalously-wet dry seasons into the cases IO-La, IO-nLa, nIO-La, and nIO-nLa shown in Table 5, we calculated spatial composites of the wind, moisture transport, two-meter air temperature, SST, OLR, and precipitation The composite results were further subtracted from the climatological data (Figure 4) in MJJAS (2000-2019; Figures 5, 7, 9, 11) to determine the oceanatmosphere anomalies in the MC (Figures 6, 8, 10, 12).

It is interesting to note that under normal dry season conditions (Figure 4), warm SSTs are found in several of

Table 5. Occurrences of different types of anomalously-wet dry seasons in Java

\begin{tabular}{llll}
\hline IOD-La & nIO-La & IO-nLa & nIO-nLa \\
\hline Aug-10 & May-00 & Jul-01 & May-01 \\
Sep-10 & Jun-00 & Aug-01 & Jun-01 \\
Aug-16 & Jul-00 & Sep-01 & May-07 \\
Sep-16 & Aug-00 & Jun-16 & Jun-07 \\
& Sep-00 & Jul-16 & May-10 \\
& Jul-07 & & May-13 \\
& Aug-07 & & Jun-13 \\
& Sep-07 & & Jul-13 \\
& Jun-10 & & Aug-13 \\
& Jul-10 & & Sep-13 \\
& & & May-16 \\
$4(13 \%)$ & $10(33 \%)$ & $5(17 \%)$ & 11 (37\%) \\
\hline
\end{tabular}


Indonesia's internal seas, such as the Java Sea, Makassar Strait, and the Banda Sea. These warm SSTs are accompanied by strong easterly monsoon winds over the southern part of the MC. Consequently, some areas in the southern part of the MC experienced low convective activity, as represented by the high OLR. As a result there was little precipitation there (Figure 4).

In the IO-La case, high atmospheric surface temperatures are distributed evenly over the MC, with the highest temperature increase occurring in northern Australia. This shows that in the IO-La case, Australia experiences warm winters (Figures 5,6-a). Increasing atmospheric surface temperatures in conjunction with moderately warm SSTs $\left(0.2-0.6^{\circ} \mathrm{C}\right)$ also occur throughout the MC (Figures 5,6-b). The temperature rise seems to affect the weakening of the easterly monsoon winds, while winds are strengthened in the Indian Ocean near Sumatra and Java, northern Australia, and the Pacific Ocean near northern Papua. Winds originating from the Indian Ocean head toward Java, while winds from the Pacific Ocean enter the Java Sea through the Moluccas and Halmahera seas (Figures 5,6-c).

The moisture transport that plays a role in triggering convective activity over Java is more dominant over the Indian Ocean than the Pacific Ocean (Figures 5,6-d and e). The mesoscale convective system centered in the Indian
Ocean extends to Sumatra, Kalimantan, and Java, causing a positive precipitation anomaly over Java during the dry season (Figure 5,6-f). This shows that a negative IOD is more influential than La Niña in increasing precipitation over Java. The influence of the Pacific Ocean, originating from the expansion of the western Pacific warm pool, appears to be concentrated locally over the Moluccas Sea. This is confirmed by a positive OLR anomaly and decreasing precipitation in Sulawesi, the Moluccas and Halmahera seas, and surrounding areas (Figures 5,6-e and f).

The negative precipitation anomaly in the northeastern MC, known as the Type I Sub-Region (Xu et al., 2019), is in contrast to previous findings showing that precipitation over the Moluccas and Halmahera seas and the surrounding areas has a strong connection with the western Pacific warm pool (Dayem et al. 2007) and is influenced by ENSO/El Niño Modoki, as inferred by increased precipitation when La Niña occurs (Ashok et al., 2007; As-Syakur et al., 2014; Chen et al., 2014; Marathe et al., 2015; Lestari et al., 2016; Wang et al., 2016; Xu and Guan 2017; Wang et al., 2018; Xu et al., 2019).

The asymmetric effect of a negative IOD and La Niña in increasing precipitation in northwestern Java has been documented by Hamada et al. (2012), who stated that a negative IOD during the dry season changes the atmospheric circulation and humidity, such that increasing SSTs in the
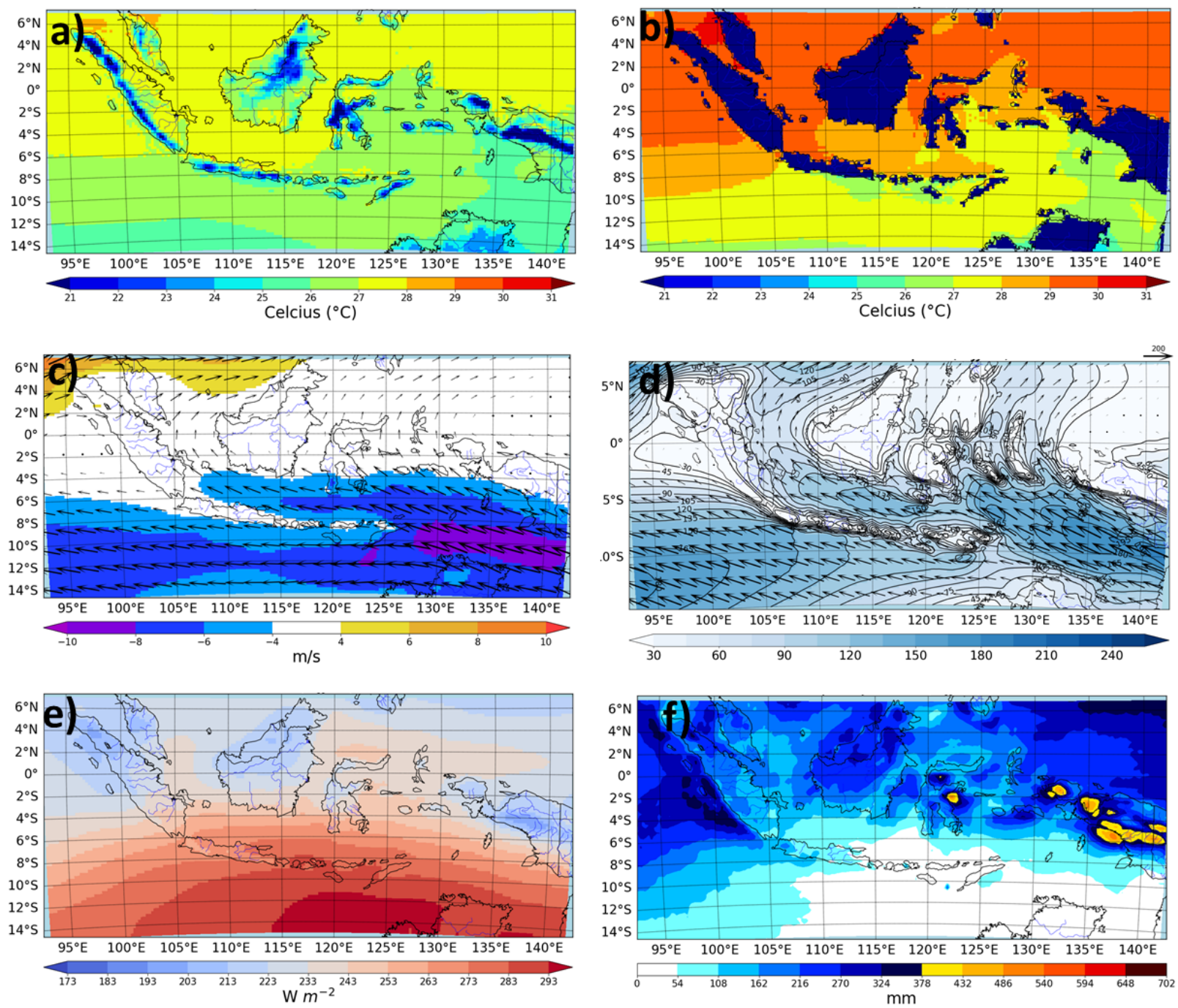

Figure 4. Map showing the climatology during the dry season (May-September) from 2000 to 2019. a) Temperature at $2 \mathrm{~m}, \mathrm{~b}$ ) sea surface temperature, $c$ ) wind at $850 \mathrm{mb}$ (shading indicates the zonal wind), d) vertically integrated moisture transport between $1000-850 \mathrm{mb}$, e) outgoing longwave radiation, and f) precipitation. 
Indian Ocean off Java and Sumatra can increase precipitation in northwestern Java more effectively than La Niña.

In the IO-nLa case, the increase in surface air temperature and SST is concentrated in the southern seas of Java (Figures 7,8-a and b). This results in the strengthening of the wind and moisture transport from the Indian Ocean to the south of Java (Figures 7,8-c and d) and triggers convective activity in parts of Sumatra and Kalimantan, but mostly in Java. This further leads to high precipitation in the southern MC, particularly the Java region (Figures 7,8-f).

The increase in precipitation occurring in parts of Sumatra and Java due to the warming SSTs in the Indian Ocean south of Java and Sumatra is consistent with studies by As-Syakur et al. (2014) and Hamada et al. (2012). Using station observation data, these studies documented the strong influence of a negative IOD on increased precipitation in western Java during the dry season.

The nIO-La case shows different characteristics. The effects of wind strength and moisture transport from the Pacific Ocean (Figures 9,10-c and d) are spread throughout the $\mathrm{MC}$, such that an increase in convective activity and precipitation is formed homogeneously, including in the northeastern seas of the MC (Figure 9,10-e and f).

However, the characteristic increase in surface air temperature and SST that occurs during La Niña (Figures 9,10-a and b) appears to be the same as in the IO-La case (Figures 5,6-a and b). The even increase in precipitation over the MC during La Niña is consistent with the study by AsSyakur et al. (2014). When La Niña occurs, SSTs increase throughout the MC, with the highest anomalies occurring in the Moluccas Sea and surrounding areas (As-Syakur et al., 2014).

In the nIO-nLa case, local SSTs play a more critical role than atmospheric surface temperatures in controlling convective activity and precipitation throughout the $\mathrm{MC}$ (Figures 11,12-c). However, two local seas in the MC are important for concentrating precipitation; namely, the southern Java Sea and Arafura Sea. This is seen in spatial data showing that the highest precipitation rates in Java occur in the southern Java Sea, Sulawesi, Arafura Sea, and northern Papua (Figures 11,12-f).

Under normal conditions in the MJJAS period, a cooling signal in the form of a cold tongue centered in the Arafura Sea is formed due to the influence of dry and cold air (Kida and Richards, 2009). In addition, strong ocean-atmosphere interactions on a local scale counteract the effects of El Niño by reducing SSTs, resulting in a clear difference between precipitation north of the equator and areas far from the equator (Kubota et al., 2011).

It is also important to note that the significant increase in rainfall over Java Island during neutral years (nIO-nLa) seen in Figures 11,12-f are inconsistent with previous results (Hamada et al., 2012; Villafuerte et al., 2015; Lestari et al., 2019; Supari et al., 2018; Kurniadi et al., 2021). This may be because the composite data was influenced by the data from May 2010 and May 2016, which were related to strong IO-La and IO-nLA events, respectively. However, this should be investigated in more detail; for example, in a high resolution coupled atmosphere-ocean model to understand the air-sea interactions on a local scale.
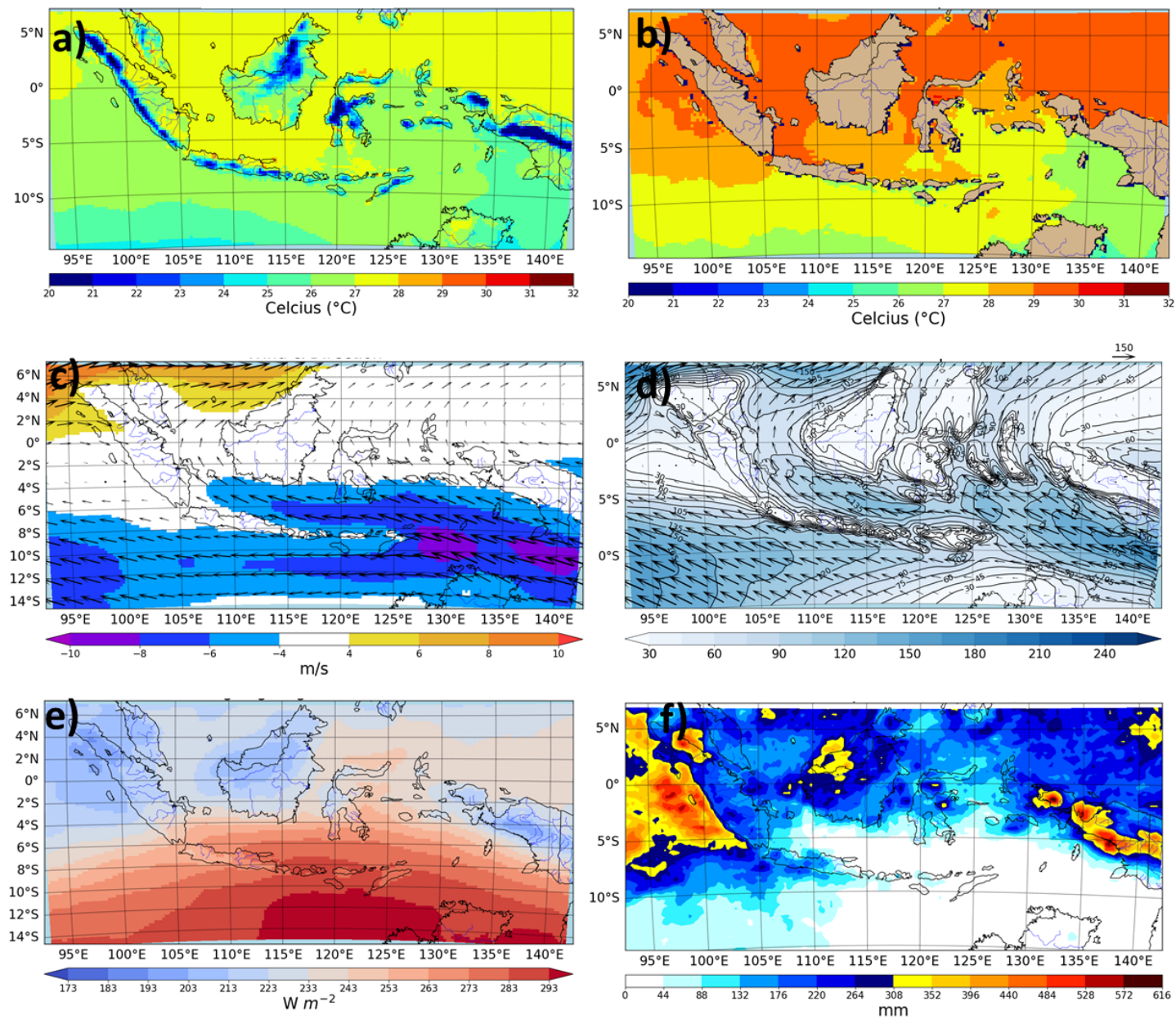

Figure 5. Same as Figure 4, but a composite of the IO-La case. 

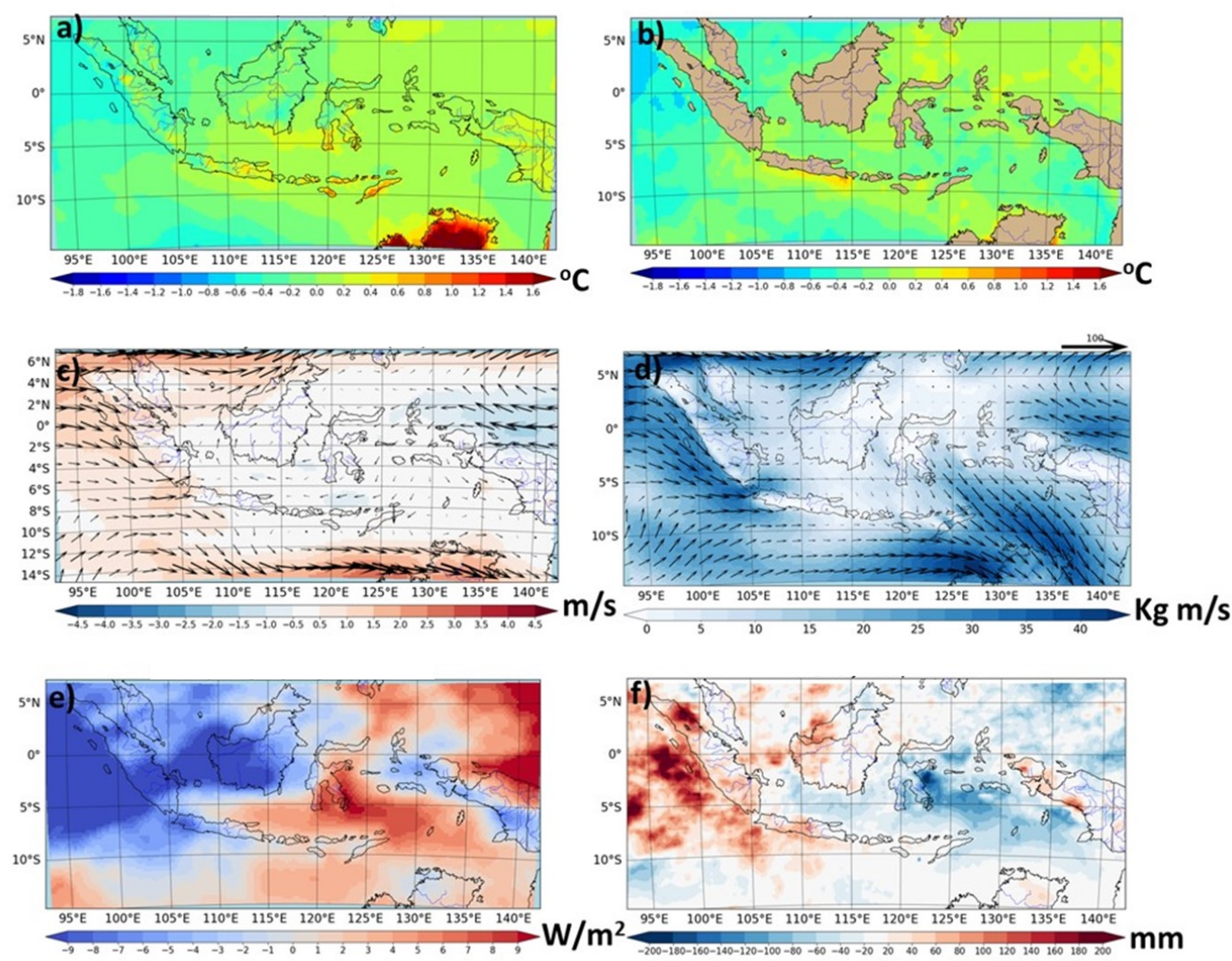

Figure 6. Ocean-atmosphere anomalies over the Maritime Continent during anomalously-wet dry seasons in the IO-La case. a) Air temperature at $2 \mathrm{~m}, \mathrm{~b}$ ) sea surface temperature, c) wind at 850 $\mathrm{mb}$ (shading indicates the zonal wind), d) vertically integrated moisture transport between 1000$850 \mathrm{mb}$, e) outgoing longwave radiation, and f) precipitation.
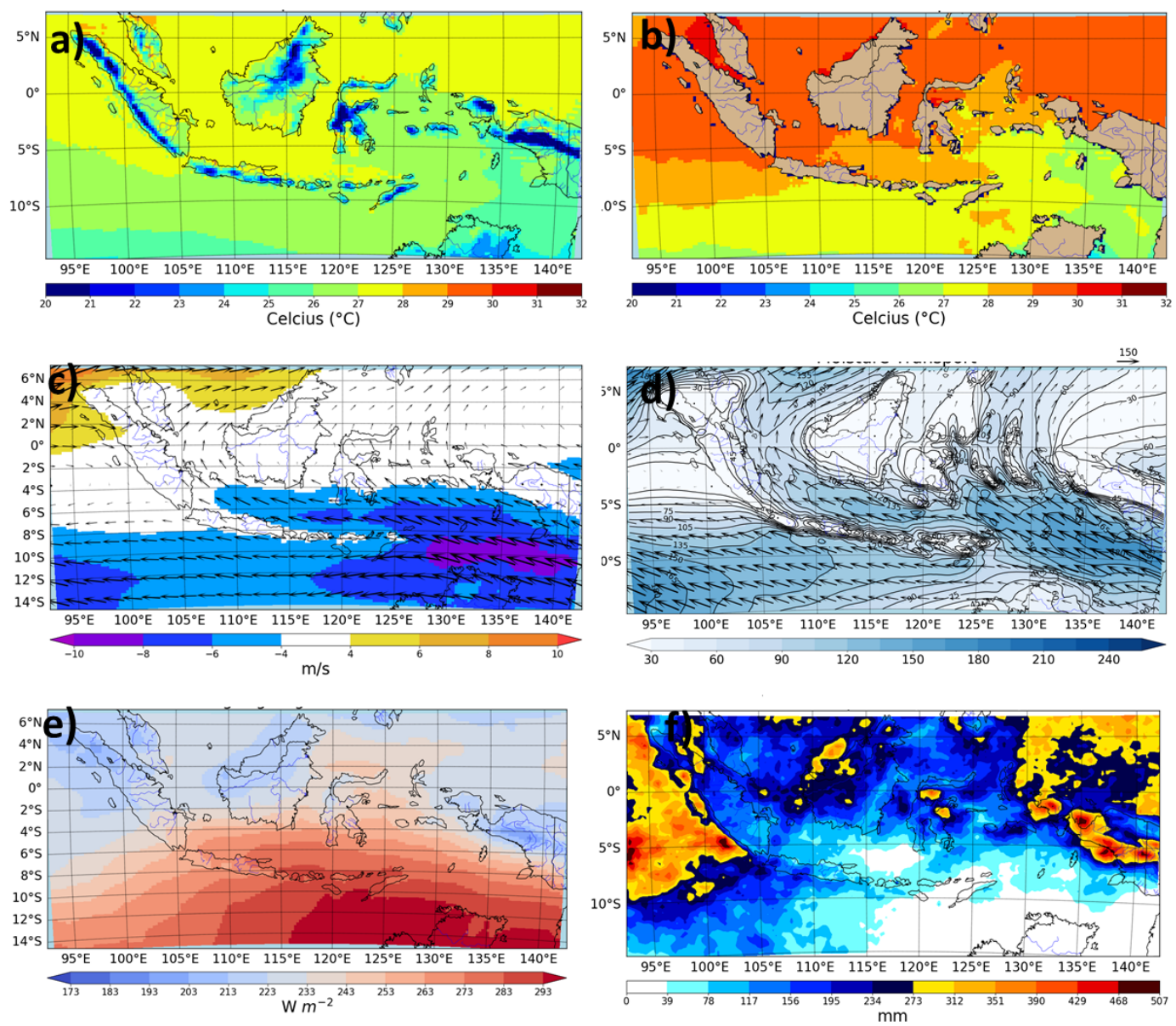

Figure 7. Same as Figure 5, but a composite of the IO-nLa case. 

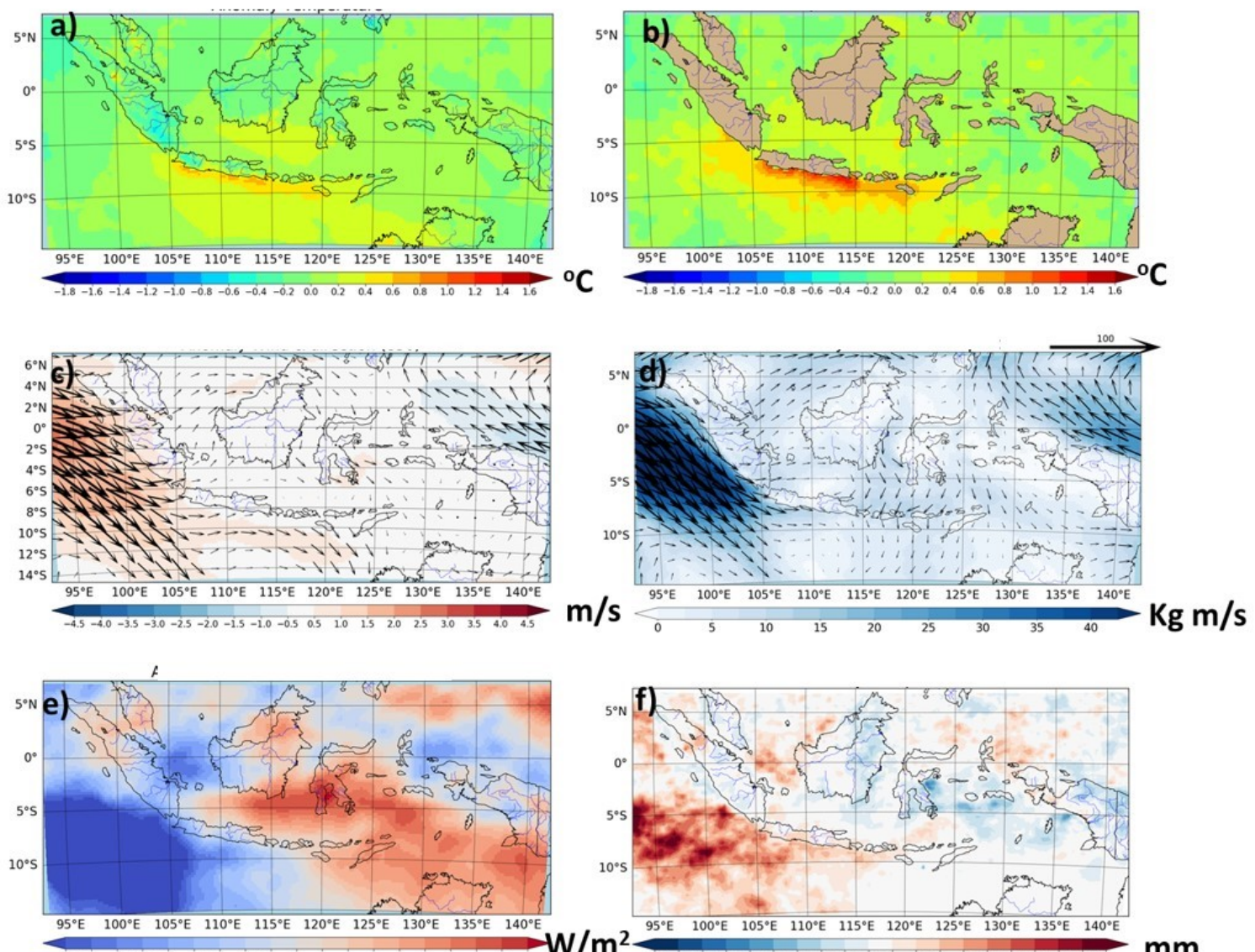

Figure 8. Same as Figure 6, but for IO-nLa events.
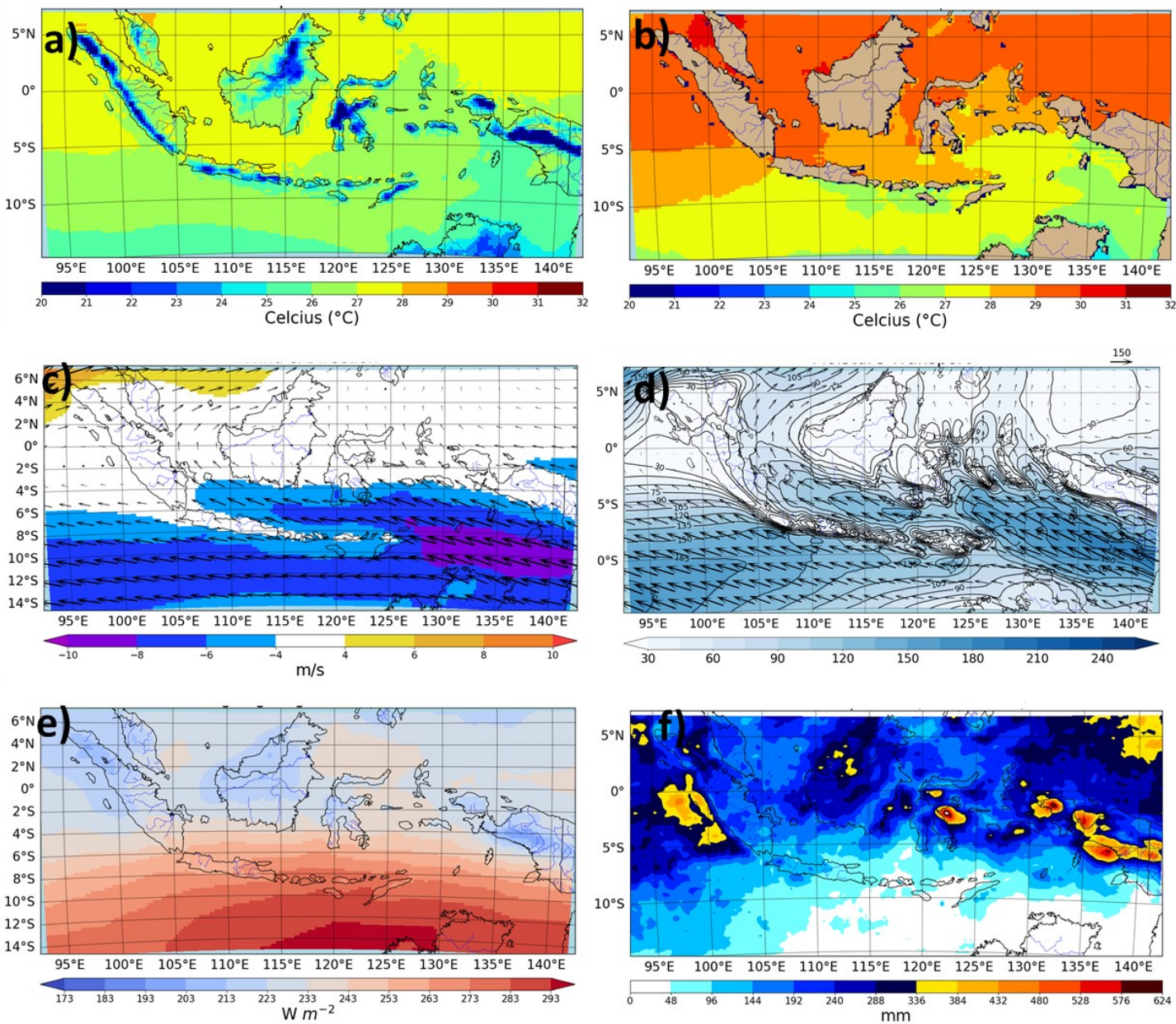

Figure 9. Same as Figure 7, but a composite of the nIO-La case. 

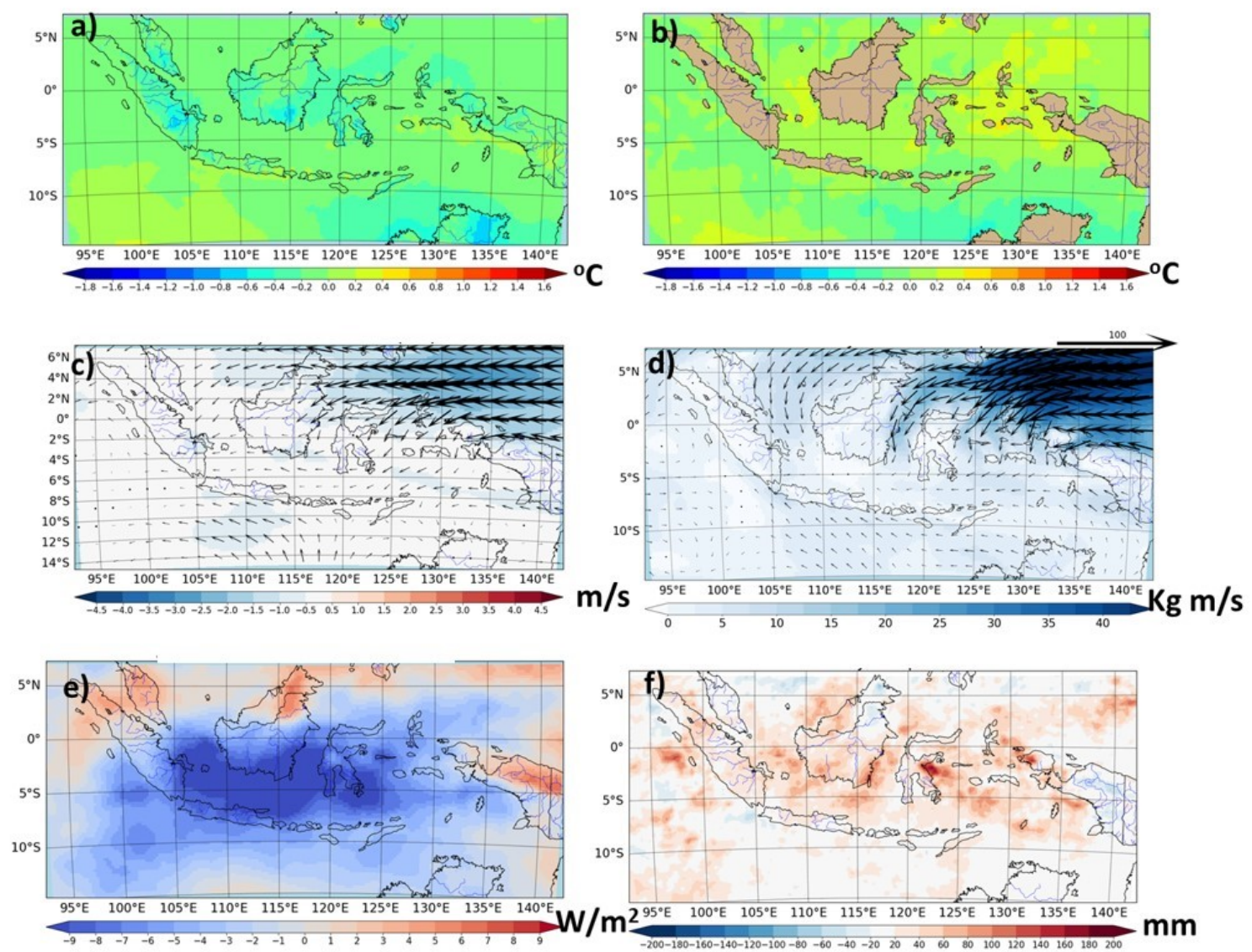

Figure 10. Same as Figure 8, but for nIO-La events.
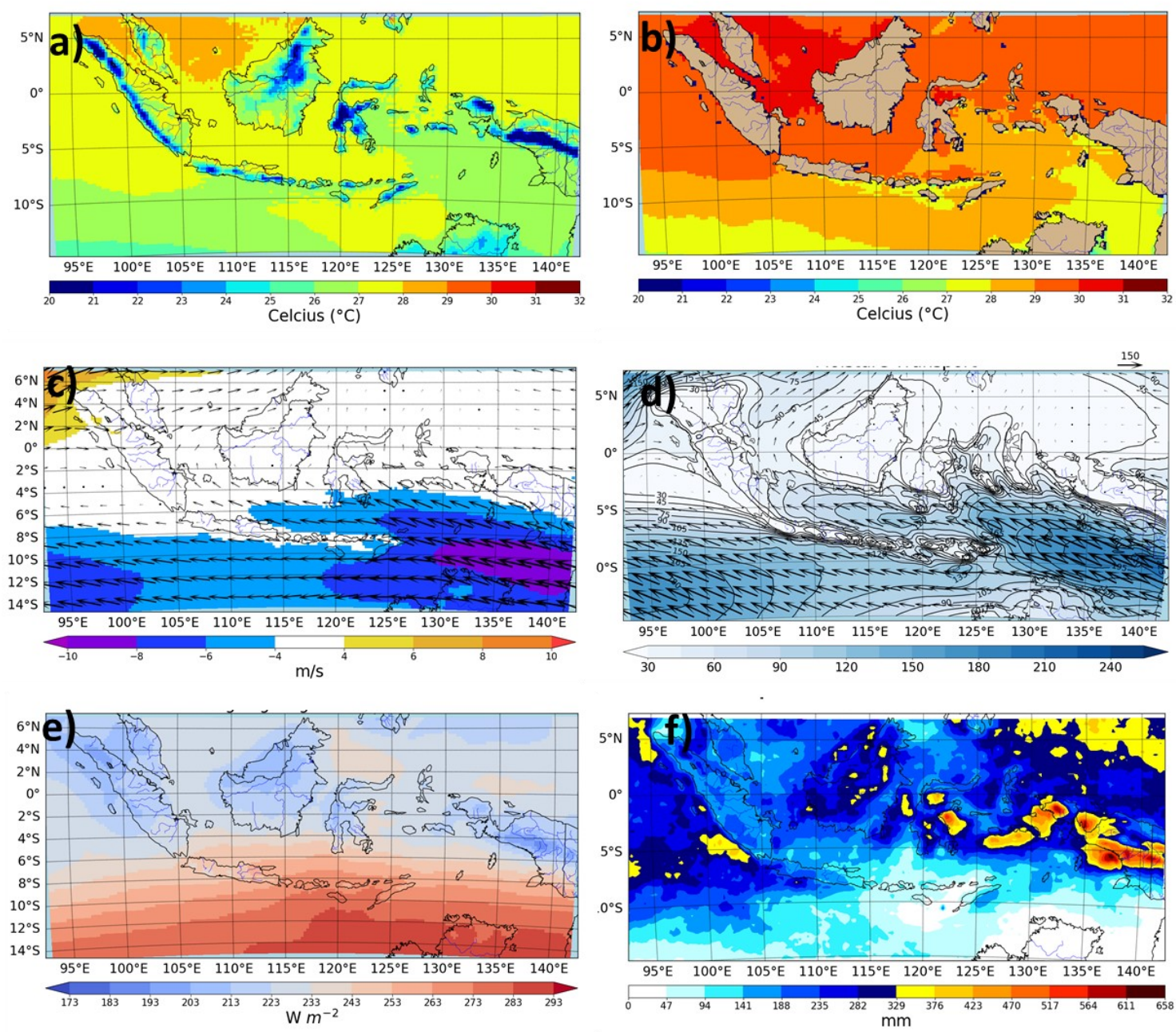

Figure 11. Same as Figure 9, but a composite of the nIO-nLa case. 

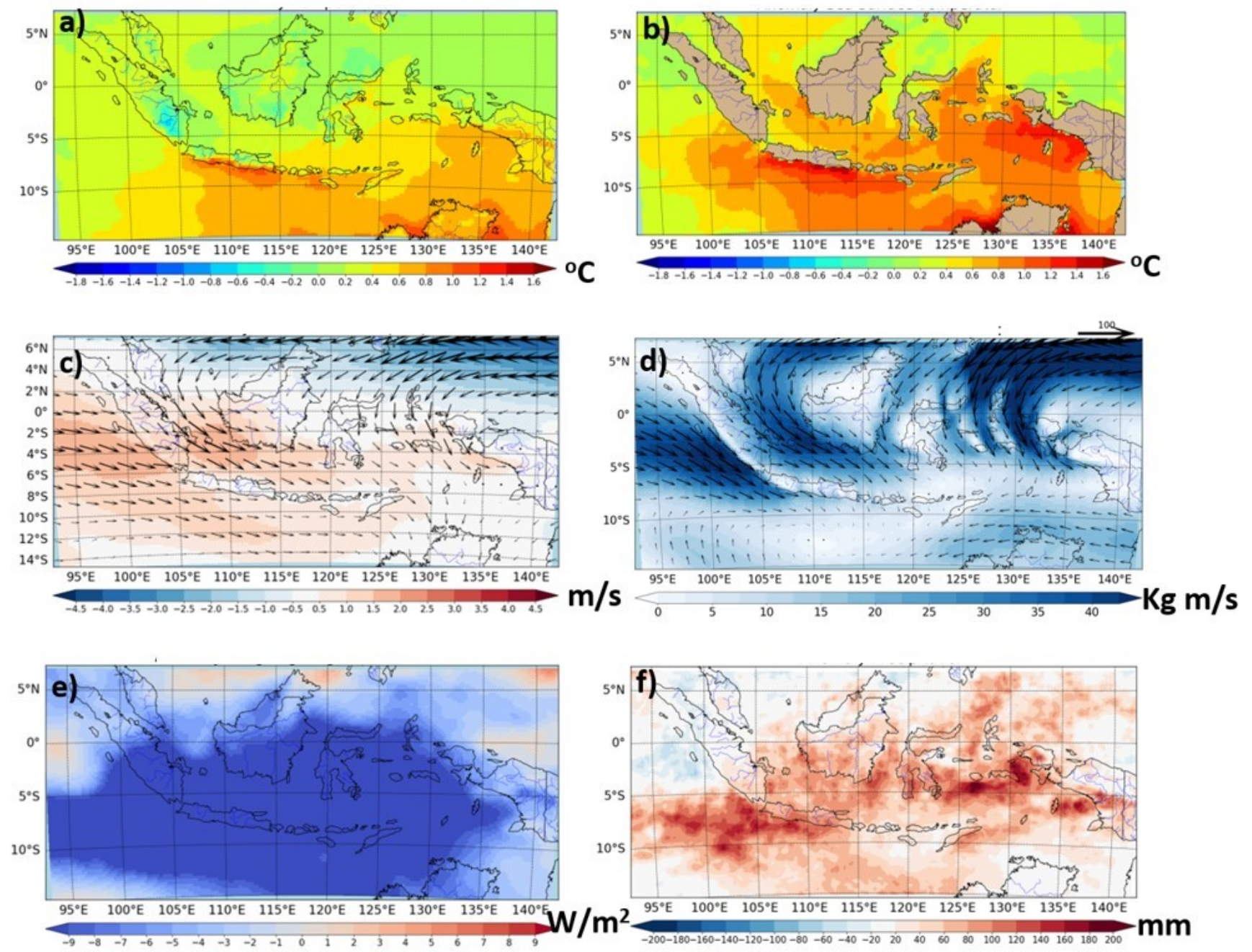

Figure 12. Same as Figure 10, but for nIO-nLa events.

\section{Conclusion}

We have studied $>20$ years of anomalously-wet dry seasons in Java, taking into account variables such as precipitation, wind, temperature, OLR, and SST from TRMM and ERA5 reanalysis data. We isolated the impacts of a negative IOD and La Niña by subtracting composite data from the climatology and grouped the results based on four situations: a negative IOD and a La Niña event (IO-La), a negative IOD and no La Niña event (IO-nLa), a neutral IOD and a La Niña event (nIO-La), and a neutral IOD and no La Niña event (nIO-nLa). We found that the contribution of local SST forcing to anomalously-wet dry seasons is significant in $37 \%$ of the events studied, whereas La Niña, IO$\mathrm{La}$, and IO-nLa are significant in $33 \%, 17 \%$, and $13 \%$ of the events studied, respectively. The contribution of the southern Java Sea in forming precipitation in Java during the dry season also appears to be dominant under neutral conditions (nIO-nLa). Specifically, the southern Java Sea plays a crucial role in causing intense precipitation to spread throughout the island. This is in contrast to the effect of La Niña alone, which has a more considerable influence on the formation of precipitation in northern Java (see Figures 7,8-f). On the other hand, a negative IOD influences precipitation intensification in southern Java. Hamada et al. (2012) have shown the significance of a negative IOD in increasing precipitation in northwestern Java. When a negative IOD coincides with La Niña (IO-La), the precipitation forming over Java occurs due to extended convective activity originating in the southern Indian Ocean. As the negative IOD strengthens, it increases precipitation, causing anomalous rainfall during the dry season in Java. This research supports the findings of previous studies that found high precipitation over Java in response to both local and remote SST warming (Hamada et al., 2012).

This study also found that SSTs in the southern Java Sea are sensitive to a negative IOD, but not to La Niña (see Figures 58 ). This result is in contrast to previous studies showing that extreme precipitation over West Java is strongly influenced by both a negative IOD and La Niña (Lestari et al., 2019). However, we found that local SST anomalies play an important role in increasing precipitation during the dry season under neutral conditions, which is in agreement with previous studies in other tropical regions (e.g., the Amazon), showing that SST anomalies driven by remote forcing in the Pacific and Atlantic Oceans affect zonal and meridional circulations (Andreolli et al., 2011). Our results indicate that a high-resolution model capable of simulating air-sea interactions over the southern Java and Arafura seas are needed to explain more detailed dynamical processes on a local scale during anomalously-wet dry seasons. 


\section{Acknowledgement}

This research was funded by the Indonesia Educational Endowment Fund (LPDP) through the Mandatory Productive Innovative Research program under National Research Priority, Decree Number: 252/Menteri Ristek/ KaBRIN/E1/PRN/2020.

\section{Authors Contribution}

Author EY drafted the initial manuscript, revised it with substantial corrections, and improved the discussion and overall content of the manuscript. Authors MFP and S produced the figures. Author IS provided input in the introduction and discussion sections. All authors were involved in discussions during the review process and read and approved the final manuscript.

\section{References}

Andreoli, R. V., de Souza, R. A. F., Kayanob, M. T., \& Candido, L. A. (2011). Seasonal anomalous rainfall in the central and eastern Amazon and associated anomalous oceanic and atmospheric patterns. International Journal of Climatology. DOI: 10.1002/ joc. 2345 .

Ashok, K., Guan, Z., Saji, N. H., \& Yamagata, T. (2004). Individual and combined influences of ENSO and the Indian Ocean dipole on the Indian summer monsoon. Journal of Climate, 17, 31413155.

As-syakur, A. R., Andyana, I. W. S., Mahendra, M. S., Arthana, I. W., Merit, I. N., Kasa, I. W., Ekayanti, N. W. Nuarsa, I. W., \& Sunarta I. N. (2014). Observation of spatial patterns on the rainfall response to ENSO and IOD over Indonesia using TRMM multi-satellite precipitation analysis (TMPA). International Journal of Climatology, 34, 3825-3839.

As-syakur, A. R., Imaoka, K., Ogawara, K., Yamanaka, M. D., Tanaka, T., Kashino, Y., Nuarsa, I. W., \& Osawa, T. (2019). Analysis of spatial and seasonal differences in the diurnal rainfall cycle over Sumatera revealed by 17-year TRMM 3B42 dataset. SOLA, 15, DOI: 10.2151/sola. 2019-039.

Chen, Z., Wen, Z., Wu, R., Zhao, P., \& Cao, J. (2014). Influence of two types of El Niños on the East Asian climate during boreal summer: A numerical study. Climate Dynamics, 43, 469-481.

Chen, W., \& Guan, Z. (2017). A joint monsoon index for East Asian -Australian monsoons during boreal summer. Atmospheric Science Letters, 18: 403-408.

Dayem, K. E., Noone, D. C., \& Molnar, P. (2007). Tropical western Pacific warm pool and Maritime Continent precipitation rates and their contrasting relationships with the Walker circulation. Journal of Geophysical Research, 112, 151-156.

Fasullo, J., \& Webster, P. J. (2003). A hydrological definition of Indian monsoon onset and withdrawal. Journal of Climate, 16, 3200-3211.

Ham, Y-G., Choi, J-Y., \& Kug, J-S. (2017). The weakening of the ENSO-Indian Ocean Dipole (IOD) coupling strength in recent decades. Climate Dynamics, 49, 249-261.

Hamada, J-I., Mori, S., Kubota, H., \& Yamanaka, M. D. (2012). Interannual rainfall variability over northwestern Jawa and its relation to the Indian Ocean Dipole and El Niño-Southern Oscillation events. SOLA, 8, 069-072.

Satyawardhana, H., Trismidianto, \& Yulihastin, E. (2018). Influence of ENSO on Deviation of The Season Onset in Java Based on CCAM Downscaling Data. IOP Conf. Series: Earth and Environmental Science, 166, 1-10, DOI :10.1088/17551315/166/1/012030

Harris, A., Rahman, S., Hossain, F., Yarborough, L., Bagtzoglou, A. C., \& Easson, G. (2007). Satellite-based flood modelling using TRMM-based rainfall products. Sensors, 7, 3416-3427.

Hatmaja, R. B., Rusmanansari, A. H., \& Radjawane, I. M. (2019). The dynamics of negative Indian Ocean Dipole (nIOD) and its relation to the anomalous high rainfall in West Java Province, Indonesia. IOP Conference Series: Earth and Environmental Science, 303, 1-9. DOI: doi:10.1088/1755-1315/303/1/012004.

Hendon, H. H. (2003). Indonesian rainfall variability: Impacts of ENSO and local air-sea interaction. Journal of Climate, 16, 1775 -1790 .

Hersbach, H., Bill, B., Paul, B., Shoji, H., András, H., Joaquín, M.-S., Julien, N., Carole, P., Raluca, R., Dinand, S., Adrian, S., Cornel, S., Saleh, A., Xavier, A., Gianpaolo, B., Peter, B., Gionata, B., Jean, B., Massimo, B., Giovanna, D.C., Per, D., Dick, D., Michail, D., Rossana, D., Johannes, F., Richard, F., Manuel, F., Alan, G., Leo, H., Sean H., Robin, J. H., Elías, H., Marta, J., Sarah, K., Patrick, L., Philippe, L., Cristina, L., Gabor, R., Patricia, d. R., Iryna, R., Freja, V., Sebastien, V., \& Jean-Noël, T. (2020). The Era5 global reanalysis. Quarterly Journal of Royal Meteorological Society. DOI: 10.1002/qj.3803 (data available at: 10.1002/qj.3803, last access: 16 May 2020)

Huffman, G. (2012). TRMM (TMPA-RT) Near Real-Time IR precipitation estimate L3 1-hour 0.25 degree $\times 0.25$ degree V7, Greenbelt, MD, Goddard Earth Sciences Data and Information Services Center (GES DISC). Doi: 10.5067/TRMM/TMPA/3HE $-\mathrm{IR} / 7$.

Huffman, G. J., Adler, R. F., Curtis, S., Bolvin, D. T., Gu, G., Nelkin E. J., Bowman, K. P., Hong, Y., Stocker, E. F., \& Wolf, D. B. (2007). The TRMM Multi-Satellite Precipitation Analysis (TMPA): Quasi-global, multiyear, combined sensor precipitation estimates at fine scales. Journal Hydrometeorology, 8，38-55. Doi: 10.1175/JHM560.1 (data available at: https://disc.gsfc.nasa.gov/datasets/ TRMM_3B41RT_7, last access: 16 May 2020).

Kajikawa, Y., Wang, B., \& Yang, J. (2009). A multi-time scale Australian monsoon index, International Journal of Climatology, DOI: 10.1002/joc.1955.

Kida, S., \& Richards, K. J. (2009) Seasonal sea surface temperature variability in the Indonesian Seas. Journal of Geophysical Research. Doi:10.1029/ 2008JC005150.

Kubota, H., Shirooka, R., \& Hamada, J-I. (2011). Interannual rainfall variability over the eastern Maritime Continent. Journal of Meteorological Society of Japan, 89A, 111-122.

Kurniadi, A., Weller E., Ki Ming S., Gyu Seong M. (2021) Independent ENSO and IOD impacts on rainfall extremes over Indonesia. International Journal of Climatology, 41(2) doi:10.1002/joc.7040.

Lestari, S., Hamada, J-I., Syamsudin, F., Sunaryo, Matsumoto, J., \& Yamanaka, M.D. (2016). ENSO influences on rainfall extremes around Sulawesi and Moluccas Islands in the eastern Indonesian Maritime Continent. SOLA, 12, 37-41.

Lestari, S., King, A., Vincent, C., Karoli, D., Protat, A. (2019) Seasonal dependence of rainfall extremes in and around Jakarta Indonesia. Weather and Climate Extremes, 24, 1-13.

Li, Y., Gupta, A. S., Taschetto, A. S., Jourdain, N. C., Luca, A. D. Done, J. M., \& Luo, J-J. (2020). Assessing the role of the oceanatmosphere coupling frequency in the western Maritime Continent rainfall. Climate Dynamics. DOI:10.1007/s0038 2020-05266 -7.

Lisonbee, J., Ribbe, J., \& Wheeler, M. (2019). Defining the north Australian monsoon onset: A systematic review. Progress in Physical Geography: Earth and Environment. DOI: 10.1177/0309133319881107.

Liu, C., Moncrieff, M. W., \& Tuttle, J. D. (2008). A note propagating rainfall episodes over the Bay of Bengal, Quarterly Journal of the Royal Meteorological Society, 134, 787-792.

Marathe, S., Ashok, K., Swapna, P., \& Sabin, T. P. (2015). Revisiting El Niño Modokis. Climate Dynamics, 45, 3527-3545.

McBride J., Haylock M R., Nochlos N. (2003). Relationships between the Maritime Continent Heat Source and the El NiñoSouthern Oscillation Phenomenon. Journal of Climate 16(17) doi:10.1175/1520-0442(2003)016<2905:RBTMCH>2.0.CO;2.

Ogino, S-Y., Yamanaka, M. D., Mori, S., Matsumoto, J. (2016). How much is the precipitation amount over the tropical coastal region? Journal of Climate, 29, 1231-1236. 
Qian, J. H. (2008). Why precipitation is mostly concentrated over islands in the Maritime Continent. Journal of Atmospheric Sciences, 65, 1428-1441.

Qu, T., Meyers, G., \& Godfrey, J. S. (1994). Ocean dynamics in the region between Australia and Indonesia and its influence on the variation of sea surface temperature in a global general circulation model. Journal of Geophysical Research, 99, 433445.

Saji, N. H., \& Yamagata, T. (2003). Possible impacts of Indian Ocean Dipole mode events on global climate. Climate Research, 25, 151 $-169$.

Supari, Tangang, F., Salimun, E., Aldrian, E., Sopaheluwakan, A., \& Juneng, L. (2018). ENSO modulation of seasonal rainfall and extremes in Indonesia. Climate Dynamics, 51, 2559-2580.

Suprapto. (2017). Tanah longsor dan banjir bencana yang mematikan di Indonesia (data tahun 2008-2017). Technical Report, BNPB.

Thompson, B., Sanchez, C., Sun, X., Song, G., Lu, J., Huang, X-Y., \& Tkalich, P. (2018). A high resolution atmosphere-ocean coupled model for the western Maritime Continent: development and preliminary assessment. Climate Dynamics. Doi:10.1007/s00382 -018-4367-0.

Trenberth, K. E. (1997). The definition of El Niño. Bulletin of the American Meteorological Society, 78, 2771-2777.

Wang, M., Guan, Z., and Jin, D. (2018). Two new sea surface temperature anomalies indices for capturing the eastern and central equatorial Pacific type El Niño-Southern Oscillation events during boreal summer. International Journal of Climatology, 38, 4066-4076.

Xu, Q., Guan, Z., Jin, D., \& Hu, D. (2019). Regional characteristics of interannual variability of summer rainfall in the Maritime Continent and their related anomalous circulation patterns. Journal of Climate, 32, 4179- 4192.

Villafuerte, M. Q., \& Matsumoto, J. (2015). Significant influences of global mean temperature and ENSO on extreme rainfall in Southeast Asia, 28, 1905-1919.

Yamanaka, M. D. (2016). Physical climatology of Indonesian maritime continent: An outline to comprehend observational studies. Atmospheric Research, 178, 231-259.

Yamanaka, M. D., Ogino, S.-Y., Wu, P.-M., Hamada, J.-I., Mori, S., Matsumoto, J. \& Syamsudin, F. (2018). Maritime Continent coastlines controlling earth's climate. Progress in Earth and Planetary Science, 5, 1-28.

Yong, B., Liu, D., Gourley, J. J., Tian, Y., Huffman, G. J., Ren, L., \& Hong, Y. (2015). Global view of real-time TRMM multisatellite precipitation analysis, Bulletin of the American Meteorological Society, 96, 283-296.

Yulihastin, E., Hadi, T. W., Ningsih, N. S., Syahputra, M. R. (2020). Early morning peaks in the diurnal cycle of precipitation over the northern coast of West Java and possible influencing factors. Annales Geophysicae, 38, 231-242. 